\title{
Endocrine Control of Psychomotor Activity in the Rat: Effects of Chronic Dexamethasone Upon General Activity
}

\author{
R J KATZ AND B. J CARROLL \\ Mental Health Research Institute, Department of Psychiatry \\ University of Michigan, Ann Arbor, MI 48109
}

(Received 20 May 1977)

\begin{abstract}
KATZ, R J AND B J CARROLL Endocnne control of psychomotor activity in the rat Effects of chronic dexamethasone upon general actvity PHYSIOL BEHAV 20(1) 25-30,1978 - In order to expand previous studies on endocrine control of activity the synthetic glucocorticoid, dexamethasone, was introduced into the water supply of adult male Sprague-Dawley rats The drug produced marked reductions in daily activity patterns which were accompanied by a redistribution of circadian patterns These changes were reversible, in part, upon discontinuation Controls for weight loss indicated this was probably not a contributing factor The present results point to an influence of the hypothalamopituitary-adrenal axis upon long-term general activity patterns
\end{abstract}

Activity Corticosteroid Dexamethasone Hypothalamic pituitary axis Locomotion

RECENT evidence from a variety of sources makes it increasingly clear that the spontaneous motor activity of the rat involves the interaction of at least two behaviorally and motivationally distinct dimensions Heretofore the majority of psychoendocrine studies have concentrated upon only one of these, wheel running, a motivationally unique form of activity [14] which is characterized by high motor initiative [1] For example, wheel running will maintain operant performance, and will often be chosen over other established reinforcers such as food or water In many ways it appears to be a primary (1 e. unconditioned) reinforcer [14] A second activity dimension, activity platform performance, or general activity, has remained largely ununvestıgated While wheel running may be a primary reinforcer, ambient locomotion upon an activity platform may represent an activity of lower incentive value, which being innately less reinforcing may be conditioned to other more highly reinforcing acts It is clear that these two forms of activity are dissociable on anatomical $[5,11]$, pharmacological [13], and motivational $[4,18]$ grounds It might therefore be anticipated that they would also be characterized by distinctive behavioral responses to endocrine manipulations

Manipulations affecting the hypothalamo-pituitaryadrenal (HPA) axis, e $g$, adrenalectomy, section of the pituitary stalk, stress, pregnancy, and pseudopregnancy as well as direct intervention with synthetic glucocorticoids such as dexamethasone are known to affect wheel running performance $[3,7,9,16]$ To date, however, there have been few equivalent investigations of the effects of steroid drugs upon general activity In one previous study [2] dexamethasone differentially affected wheel running but had few effects upon activity recorded in a shuttle box This supports a distunction between 2 separable forms of activity and suggests that further investigation is called for The present investigation therefore examined the effects of chronic dexamethasone upon the spontaneous locomotor patterns of the rat under a number of environmental conditions

The first experiment was designed to assess the possible influence of dexamethasone upon activity platform performance under the influence of an imposed light/dark cycle Previous reports have generally employed imposed lighting cycles and have found that corticostero1ds may selectively alter activity in specific portions of the activity cycle under such conditions [8]

The second experiment examined the role of weight loss (which normally follows chronic dexamethasone administration) in causing the altered activity patterns seen in the first experiment, while the thurd experiment examined the contribution of an imposed light/dark cycle to the reported drug effects

\section{METHOD}

\section{Antmals}

The animal pool for the 3 experiments consisted of 21 adult male Sprague-Dawley rats obtained locally (Spartan Farms, Haslett, MI) weighing $350-500 \mathrm{gm}$ at the start of the expenment Anumals were housed individually in $48 \times$ $27 \times 20 \mathrm{~cm}$ polypropylene cages (Scientıfic Products series 140) With the exception of Experiment 2, in which access to food was limited, food and water were avallable ad lib throughout the experiment, and with the exception of 
Expenment 3, light/dark cycles of $12 \mathrm{hr}$ each (light onset and offset at 8 and $20 \mathrm{hr}$ respectively) were maintained by automatically programmed artificial lighting In the third experiment animals were maintained under a constant illumination of approximately 500 milliphots intensity provided by GE-F96T12R fluorescent lights These lights emitted a deep red llumination $(\lambda=600-700 \mathrm{nM})$ which was subliminal for the animals Four animals each were used in each of the three experiments for the assessment of behavioral effects, whlle the remaining 9 animals were used as a control group for a variety of assays designed to directly assess the physiological effects of dexamethasone

\section{Apparatus}

Anımals were maintained in their home cages throughout all stages of the reported experiments In each of the 3 behavioral experiments the cages were placed upon four 48 $\times 41 \mathrm{~cm}$ field sensitive activity monitor platforms (Stoelting SA-1 566, 1562, 1570) operating on a selective mode for the detection of gross body movement Platforms were initially matched for sensitivity

\section{Procedure}

In all 3 experiments subjects were allowed an initial experimental habituation period of 15 days, the last 10 days of which involved placement upon the activity platforms Since Experiment 3 involved a radical shift in lighting for the subjects it should be noted that based upon our procedure 2 weeks habituation to the constant dark environment preceded any experimental recording Following this penod activity was monitored on an hourly basis with automatically programmed recording equipment The initial 7 days of recording served as a baseline for the evaluation of any drug effects On Hour 12 of Day 7 dexamethasone was introduced into the drinking water of all animals (Experiments 1,3) For Experiment 2, food was restricted to $10 \mathrm{gm}$ per day administered randomly during the day beginning at this time This feeding regimen produced a weight loss which was equivalent to that induced by dexamethasone Recording continued for an additional 7 days At the close of the second week of the experiment all animals were weighed, and given one of two treatments Two animals were returned to the activity platforms for an additional 7 days of monitoring with drug discontinued This served as a recovery period dunng which the reversibility of drug effects was examined The remaining two subjects were sacrificed to determine the physiological effects of drug administration Animals were killed by decapitation (at $\mathrm{hr}$ 12) and bloods were collected in siliconized tubes for plasma corticosterone determination by the method of Murphy [12] In addition the adrenal glands were dissected and weighed at the time of death Similar procedures were carried out for the remaining animals at the close of recovery testing

\section{Drugs}

Dexamethasone sodium phosphate (Hexadrol, Organon) was diluted to a final concentration of $5 \mu \mathrm{g} / \mathrm{ml}$ in a tap water vehicle This dosage was based upon previous reports $[2,18]$ In the present experiments this represented an effective darly dose range of $150-250 \mu \mathrm{g}$

\section{Statistical Procedures}

A variety of techniques were employed in the analysis of data The existence of a circadian rhythm was established by spectral analysis of individual animals Subsequent to the demonstration of daily activity patterns, changes in mean activity were demonstrated by a Freidman 2-way analysis of variance [17] In order to equate changes in the performances of individual animals all analyses were carried out upon percentage transformed scores Means for daly activity were individually computed for the initial seven days of baseline activity and all scores were expressed and analyzed as percentages of the activity of the first week Finally in order to assess any possible changes in the daily distribution of activity, all hourly data were transformed to percentages of within day total activity, and analyzed via profile analysis, with T-tests for the parallelism of activity profiles (Profile analysis is a multivariate technique of mathematical modeling that compares several (in the present case, 3 ) commensurable sets of repeated observations ( $1 \mathrm{e}$, a profile of observations - in the present case, hourly counts of activity) In essence it asks whether a treatment (drug administration) has produced changes in one or more sets of observations Looking to typical profiles of effects (e g, Fig 5), the analysis asks whether the slopes of adjacent data points are the same or different across conditions)

All analyses, except the analysis of variance, were performed upon the computer facilities of the University of Michigan, and documentation for all procedures was been published [6]

\section{RESULTS}

\section{Experiment 1}

Dexamethasone effects upon activity (light entrained) Spectral analysis revealed a significant circadian rhythm for all animals In all cases maximum spectral density occurred at approximately $24 \mathrm{hr}$ (range 23 9-24 2), and in all cases this peak was at least 20 -fold greater than any other interval and did not appear to be affected by drug treatment Thus a $24 \mathrm{hr}$ rhythm of activity was present in all anumals Daily average activity patterns are presented in Figs 1 and 2 It may be seen (F1g 1) that mean activity was stable during the initial baseline recording penod, and furthermore that it declined significantly during chronic dexamethasone treatment $\left(X_{\mathrm{r}}^{2}=264, d f=13, p<005\right)$ Discontinuation of dexamethasone produced a partial recovery of this activity measure $\left(F_{1} g\right.$ 2) which was in fact significant $\left(X_{r}^{2}=141\right.$, $d f=6, p<005$ ) Thus, dexamethasone appeared to reduce average daily activity

Changes in dally activity distribution are presented in Fig 3 In all cases the majority of activity occurred during light offset and it might be seen that there was a trend for peak activity to occur later in the cycle as the experiment progressed This trend continued through recovery, and T-square tests for the parallelism of profiles indicate a maximum root of 125 with $d f=2,10,29$, this yields a significance level of $p<0001,1 \mathrm{e}$, the profiles changed during and after drug administration At the close of the experiment the animals had lost approximately $20 \%$ of their initial body weight In order to evaluate the contribution of weight loss per se to the present findings a second group of rats was subjected to non-steroidal weight loss (Experiment 2) 


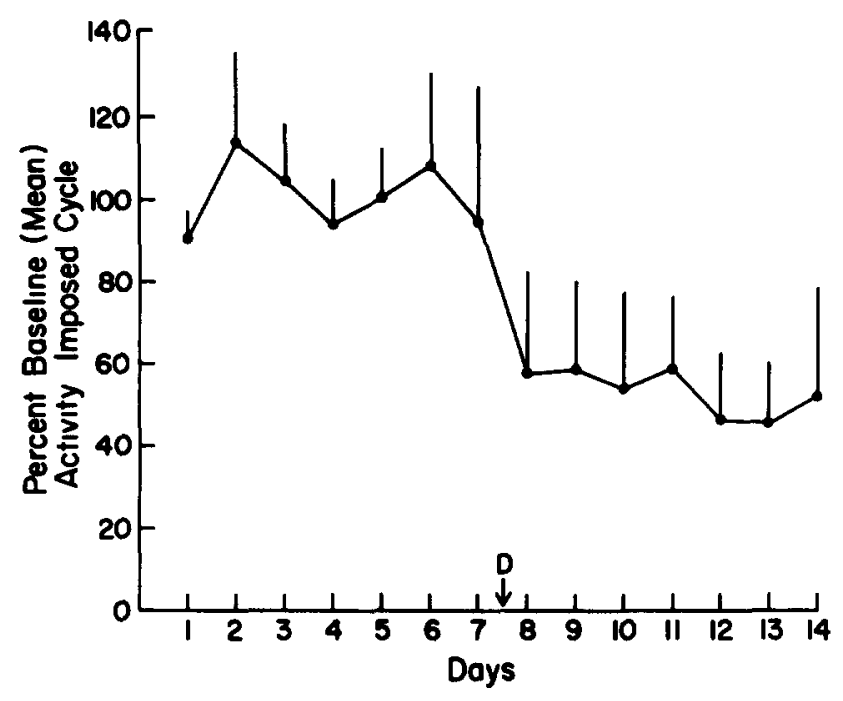

FIG. 1. Effects of dexamethasone upon mean activity (+ SEM, imposed light/dark cycle), $\mathrm{D}=$ dexamethasone introduction

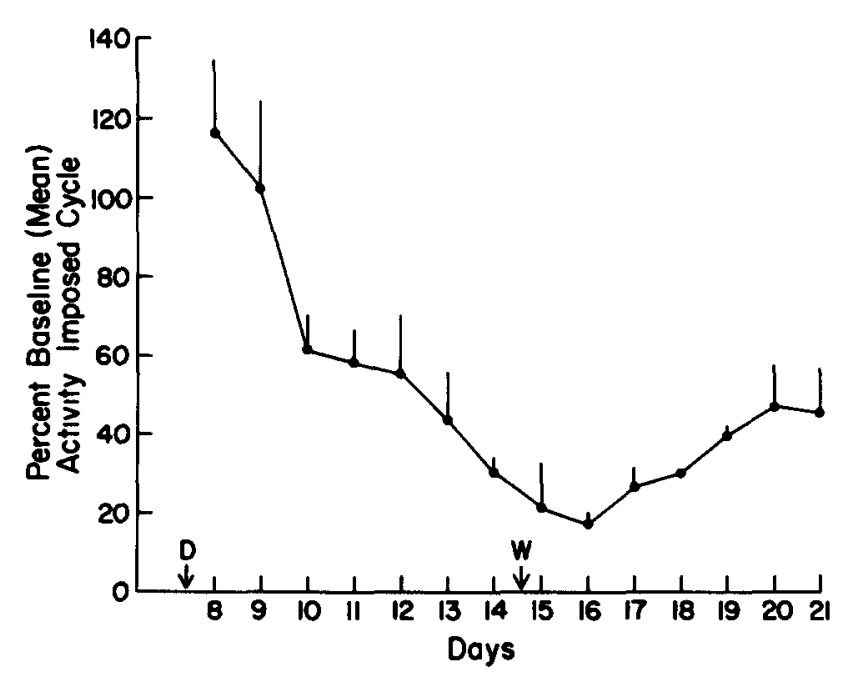

FIG 2 Recovery following dexamethasone mean activity (+ SEM, imposed cycle), $\mathbf{D}=$ dexamethasone administration, $W=$ recovery (water)

\section{Experiment 2}

Food restriction without steroid administration As in Experument 1 anumals showed evidence of circadian activity based upon spectral analysis In all cases the major distribution of spectral density was approximately $24 \mathrm{hr}$ (range 23 8-243), and this peak of activity was again at least 20 times greater than any other interval The effects of chronic food restriction are presented in Figs 4-6 In marked contrast to Experiment 1, food restriction produced increases in mean ( $\left.F_{1 g} 4\right)$ activity and this increase was significant (Friedman 2-way ANOVA $\mathrm{X}_{\mathrm{r}}^{2}=231, d f=$ $13, p<005)$ Furthermore, return to ad lib feeding produced a reduction in mean activity ( $F_{1 g} 5$ ) and this also was significant $\left(X_{r}^{2}=143, d f=6, p<005\right)$

While activity profiles were virtually unchanged in the first two weeks of testıng ( $\left.F_{1 g} 6\right)(1 \mathrm{e}$, prerestriction and restriction conditions) the activity profile underwent a

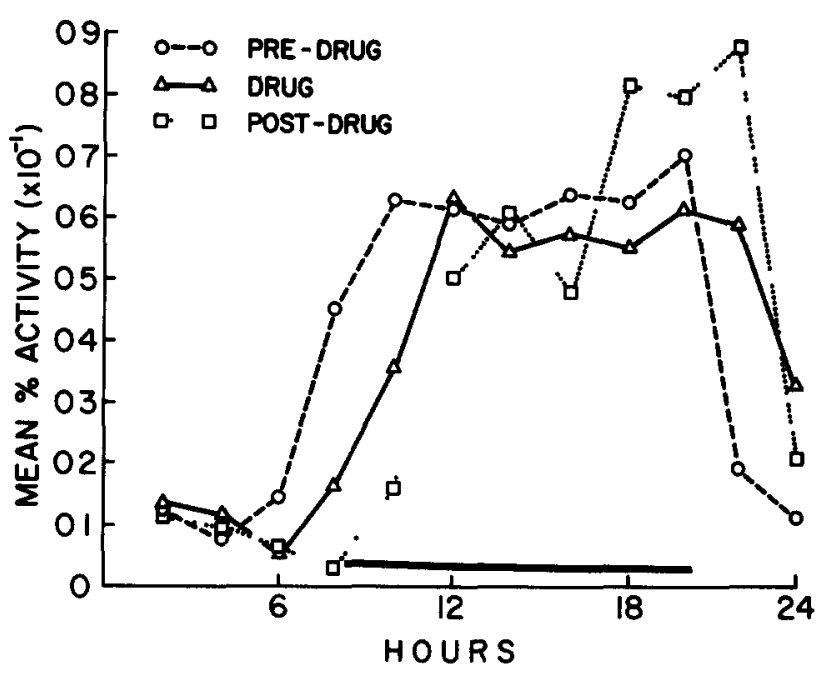

FIG 3 Changes in daily activity profile (imposed cycle), drug effects and recovery

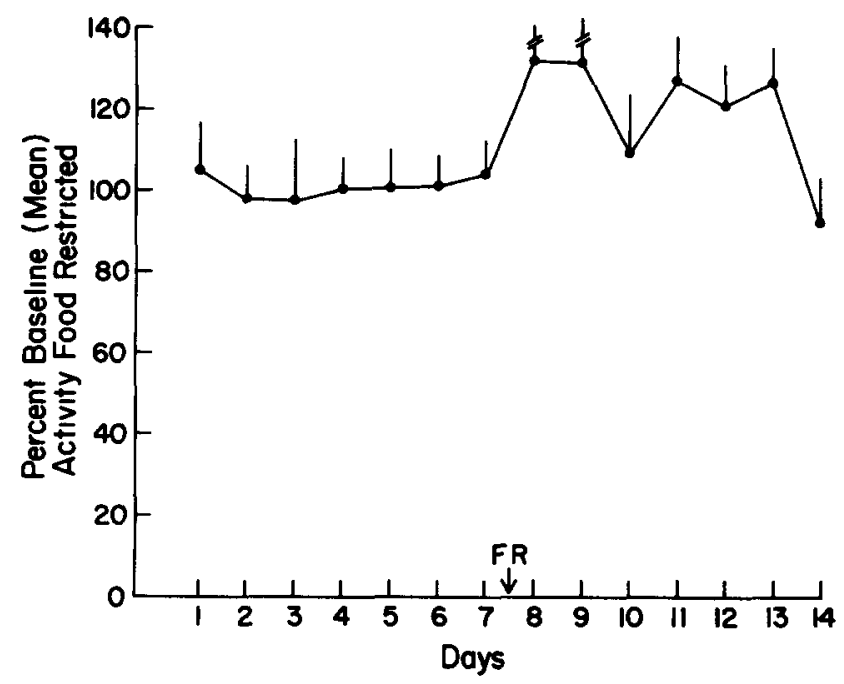

FIG 4 Effects of food restriction upon mean activity (+SEM, food restricted), $F R=$ food restriction

considerable change during recovery, and this change was significant ( $\max$ root $=098, d f=2,10,285, p<00001$ ) The change durng the post restriction period consisted of an increase in peak activity in relation to non-peak penods, $1 \mathrm{e}$, the peak curve subtended a larger area

\section{Experiment 3}

Dexamethasone administration without an imposed light/dark cycle As in the previous experiments, a circadian activity rhythm was present by spectral analysis, the maximum peak for all animals was approximately $24 \mathrm{hr}$ (23 9-24 5), and this peak was also at least 20 times greater than any other interval The results of the behav1oral experiments are presented in Figs 7-9 In general the findings were similar to those seen in Experiment 1 Mean activity was stable over the initial baseline period and drug introduction produced a rapid and significant decline ( $F_{1 g}$ $7, \mathrm{X}_{\mathrm{r}}^{2}=453, d f=13, p<0001$ ) While drug discontinuation 


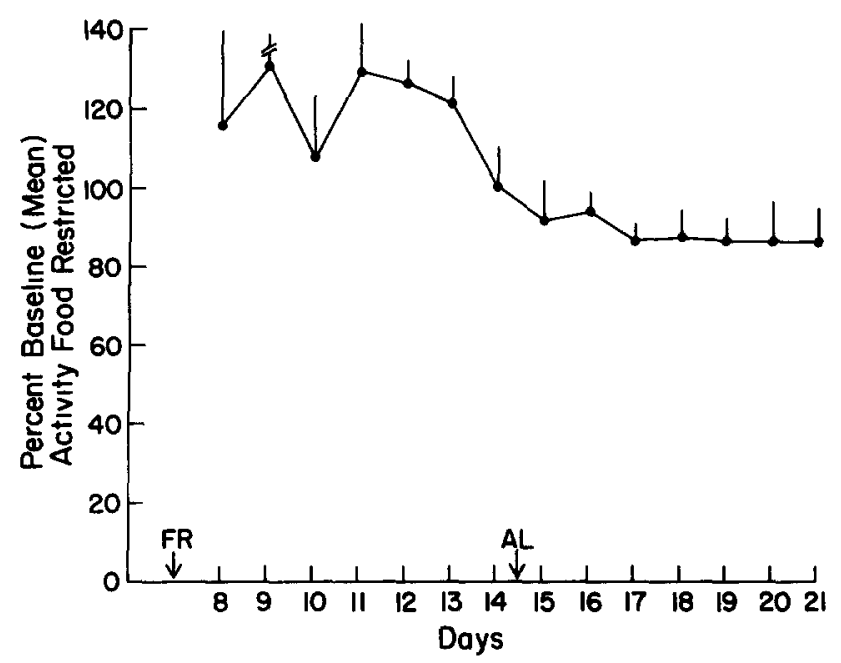

FIG 5 Recovery following food restriction mean (+ SEM), FR = food restriction, $\mathrm{AL}=$ ad libitum feeding

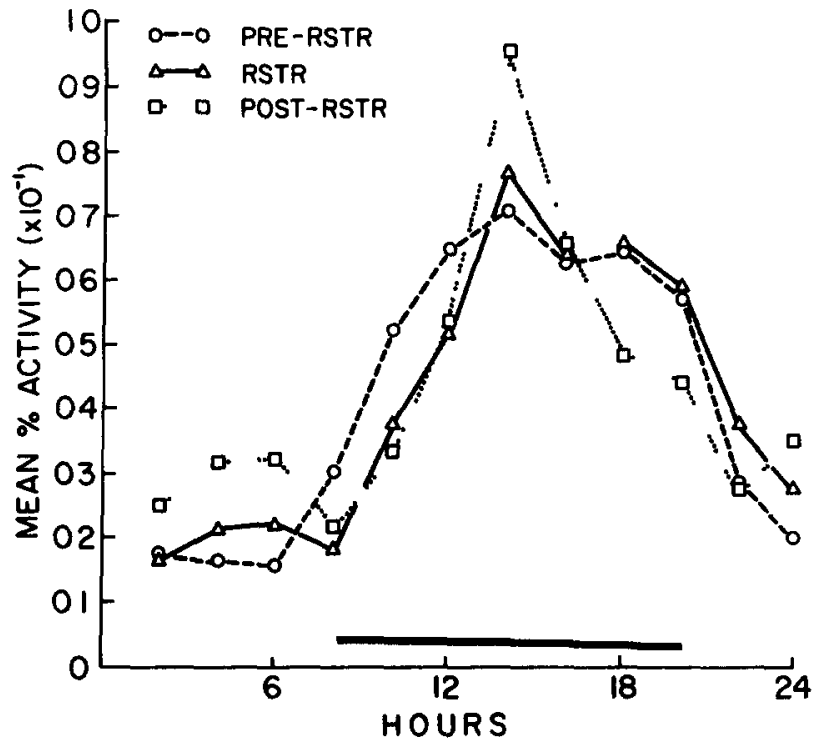

FIG 6 Changes in dally activity profile (food restriction and recovery)

brought about increases in activity the large variability in improvement resulted in this increase being non-significant $\left(\mathrm{F}_{1 \mathrm{~g}} 8, \mathrm{X}_{\mathrm{r}}^{2}=58, d f=6, p<05\right.$ )

Profile analysis revealed a significant shift in daily activity patterning coincident with drug administration Additional, albeit minor, changes continued upon drug discontinuation (Fig 9) The change was significant using a T-test for profile parallelism (Max root $=2218, d f=$ $2,10,29, p<00001$ )

\section{Changes in Body Weight and HPA Activity}

The animals treated with dexamethasone lost between $15 \%$ and $20 \%$ of their ongunal body weight, and regained about half of this loss during the recovery period (Table 1 , Experiments 1 and 3) The animals in Experiment 2 (food restriction) lost and regained similar amounts of weight

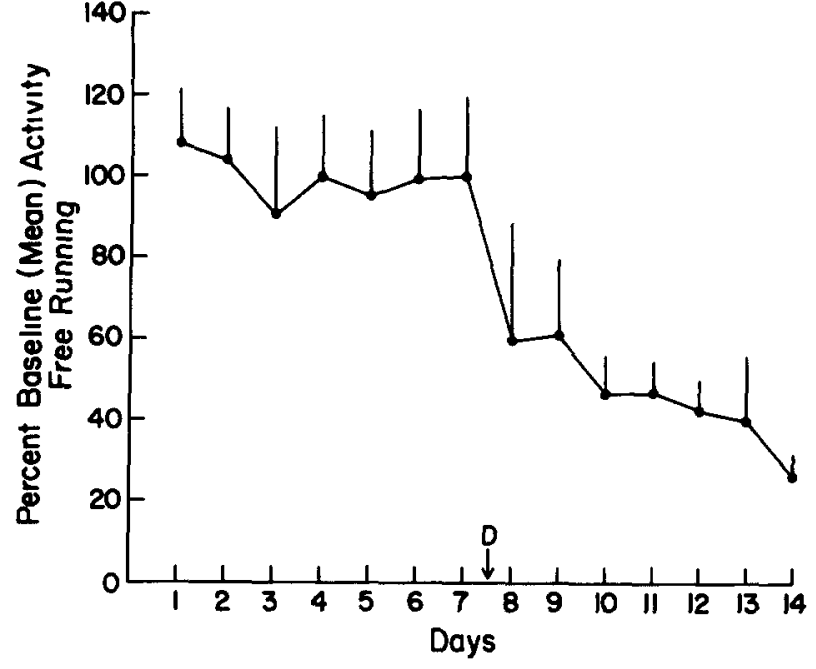

FIG 7 Effects of dexamethasone upon mean actıvity (+ SEM, free running), $\mathrm{D}=$ dexamethasone introduction

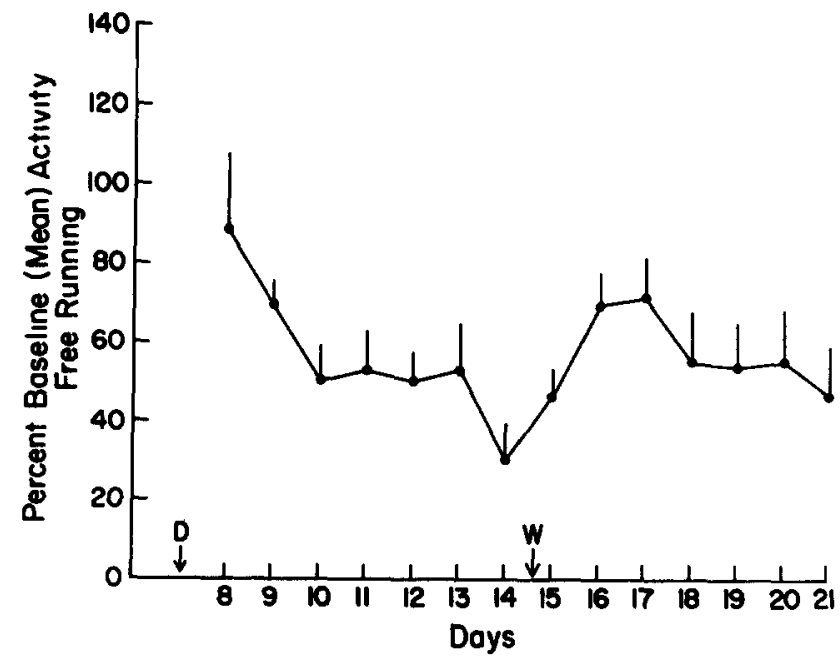

FIG 8 Recovery following dexamethasone mean activity (+ SEM, free running), $\mathrm{D}=$ dexamethasone administration, $\mathrm{W}=$ recovery (water)

As expected, the groups treated with dexamethasone showed virtually complete suppression of plasma cort1costerone levels They also developed adrenal atrophy One week after the steroid was discontinued there was only partial recovery of adrenal weights and plasma corticosterone levels No remarkable changes in these measures of HPA activity were observed in the animals subjected to food restriction and weight loss (Table 1)

\section{DISCUSSION}

Chronic treatment with dexamethasone produced profound and long-lasting changes in both HPA function and general activity patterns The circadian penodicity of general motor activity was not affected a penod length of $24 \mathrm{hr}$ was maintained throughout all the experiments However, mean daily activity was reduced by dexamethasone Redistribution of the total dally activity profile was observed also These behavioral effects of dexamethasone 
TABLE 1

PHYSIOLOGICAL EFFECTS OF DEXAMETHASONE

\begin{tabular}{lccccccc}
\hline \multicolumn{1}{c}{ Group } & $\begin{array}{c}\text { Control } \\
(\mathrm{n}=9)\end{array}$ & $\begin{array}{c}\text { Experiment } 1 \\
(\mathrm{n}=2)\end{array}$ & $\begin{array}{c}\text { Recovery 1 } \\
(\mathrm{n}=2)\end{array}$ & $\begin{array}{c}\text { Experiment 2 } \\
(\mathrm{n}=2)\end{array}$ & $\begin{array}{c}\text { Recovery 2 } \\
(\mathrm{n}=2)\end{array}$ & $\begin{array}{c}\text { Expenment 3 } \\
(\mathrm{n}=2)\end{array}$ & $\begin{array}{c}\text { Recovery 3 } \\
(\mathrm{n}=2)\end{array}$ \\
\hline $\begin{array}{l}\text { (\% change } \\
\text { ln weight) }\end{array}$ & $+20 \pm 11$ & $-192 \pm 21^{*}$ & $-120 \pm 11^{*}$ & $-150 \pm 13^{*}$ & $-70 \pm 20^{*}$ & $-140 \pm 20^{*}$ & $-70 \pm 10^{*}$ \\
$\begin{array}{l}\text { adrenal } \\
\text { weight } \\
\text { (In mg) }\end{array}$ & $700 \pm 20$ & $400 \pm 100^{*}$ & $500 \pm 50^{*}$ & $650 \pm 50$ & $630 \pm 50$ & $450 \pm 100^{*}$ & $500 \pm 50^{*}$ \\
$\begin{array}{l}\text { plasma } \\
\text { corticosterone } \\
(\mathrm{In} \mu \mathrm{g} / 100 \mathrm{ml})\end{array}$ & $242 \pm 23$ & $11 \pm 20^{*}$ & $54 \pm 02^{*}$ & $305 \pm 25$ & $272 \pm 26$ & $20 \pm 075^{*}$ & $46 \pm 22^{*}$ \\
\hline
\end{tabular}

${ }^{*} p<005$ in comparison to control

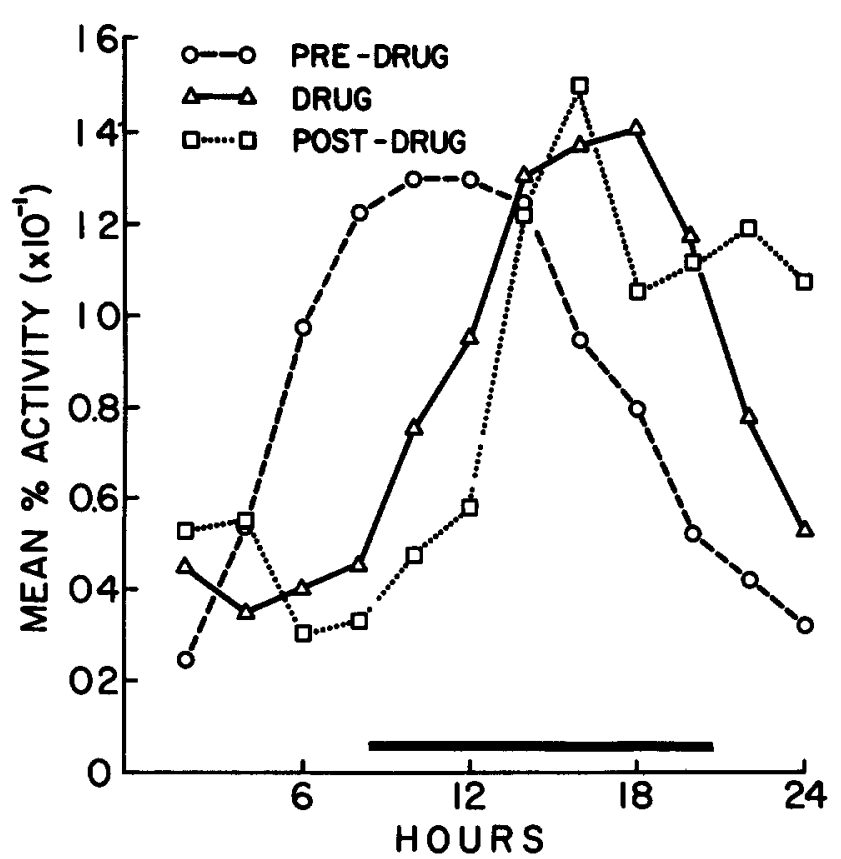

FIG 9 Changes in darly activity profile (free running) drug effects and recovery

were not a function simply of the concomitant weight loss, since food restriction caused opposite changes in the activity measures (Experiment 2) This effect of food restriction has been described previously [18]

Our results with general activity are directly opposite to previous reports $[2,8]$ indicating dexamethasone increased the wheel-running activity of rats and that food restriction caused the same effect as dexamethasone on wheel-running activity [2] A previous report concluded that the effect of the steroid was related to the weight loss This was not the case in our own experiments with general activity as the dependent vanable

This last report [2] has also noted that neither food restriction nor dexamethasone affected general activity in a shuttle apparatus While this may appear contradictory to the present study it should be noted that a number of procedural differences exist between these 2 studies Drug dosage, age, sex, strain of rat, and testing conditions all differ, and any of these may have contributed The previous report utilized a circumscribed part of the light cycle for recording, and it therefore might be noted that (a) the use of restncted out of home cage recording techniques may produce a qualitatively different syndrome from chronic home cage recording (e g, [19]) and (b) attention to $F_{1 g} 5$ indicates that major changes in activity occurred when baselines were high rather than low In fact, there is a relative increase in activity during the light cycle and only few absolute changes in activity may have been present during the normally low baseline (In Experiment 1 Friedman ANOVA found no significant lowering of daylight activity during drug administration $\left(\mathrm{X}_{\mathrm{r}}^{2}=51, d f=13\right.$, $p>0$ 05)

The measures of HPA activity (adrenal weights and plasma corticosterone levels - Table 1) indicated that profound suppression of the HPA axis was produced by the dexamethasone treatment, and that only minumal recovery of the axis had occurred one week after the steroid was withdrawn The half-life of dexamethasone in rats is 6-8 hr in plasma and brain tissue Thus by the end of one week after withdrawal of dexamethasone the rats had continued secondary adrenal atrophy, but low effective glucocorticond levels During this recovery week the mean dally activity measures returned towards baseline values, whereas the distribution of daily activity remained abnormal The reductions in total daily activity may therefore be related to the high glucocorticoid concentrations during dexamethasone treatment, while the redistribution of daily activity may be related to other changes including continued disruption of adrenal function No measures of central hypothalamo-pituitary function were taken, however clinical evidence suggests prolonged suppression of regulation after high doses of dexamethasone (e $g$ [10]) The possible contributions of altered ACTH and CRF release to our results is unknown, but must be considered, since these hormones do have behavioral effects themselves [16]

The contrast between our findings with general motor activity and the previous reported effects of dexamethasone on wheel-running activity (which is a highly motivated behavior) points to a need for careful operational definitions when steroid effects on motor behavior are being considered 


\section{ACKNOWLEDGEMENTS}

The authors gratefully acknowledge support provided by the National Institute of Mental Health through the University of Michigan (Grant No MH 07417) We are additionally grateful to Mr Dan Fox of the Statistical Research Laboratory of the
University of Michigan for his assistance and advice regarding the analysis of these data, Nancy Bennett and Bob Shea for additional assistance in statistics, Jerry Schielke for expert technical assistance in the assay of corticosterone, and Drs Brad Powers and Meir Steiner for their comments

\section{REFERENCES}

1 Barbeau, A Brology of the Striatum In Biology of Brain Disfunction, Vol 2, edited by G Gavel New York Plenum, $1973 \mathrm{pp} \mathrm{333-350}$

2 Beatty, W W, C W Scouten and P A Beatty Different effects of dexamethasone and body weight loss on two measures of activity Physiol Behov 7: 869-871, 1971

3 Brain, $P$ F Mammalian behavior and the adrenal cortex-A review Behav Biol 7 453-477, 1972

4 Campbell, B A Theory and Research on the effects of water deprivation on random activity in the rat In Thirst, edited by M Wayner New York Pergamon, 1964

5 Capobianco, S and L W Hamilton Effects of interruptions of limbic system pathways on different measures of activity Physiol Behav 17: 62-72, 1976

6 Fox, D and K E Guire Documentation for Midas Statistical Research Laboratory, Ann Arbor University of Michigan, 1976

7 Gnffiths, W J, Jr Effect of adrenalectomy on incidence of audiogenic seizures among domestic and wild rats $J$ comp physiol Psychol 42. 303-312,1949

8 Kendall, J W Dexamethasone stımulation of running activity in the male rat Hormones Behav 1: 327-336, 1970

9 Leshner, A I The adrenal and the regulatory nature of running wheel actıvity Physiol Behav $6551-558,1971$

10 Livanou, T, D Gerriman and V H T James Recovery of hypothalamus-pituitary adrenal function after corticosteroid therapy Lancet 2: 856-859, 1967

11 Lynch, G Separable forebrain systems controlling different manifestations of spontaneous activity $J$ comp physiol Psychol 70. 48-59, 1970
12 Murphy, B E P Some studies of the protein binding of steroids and their application to the routine micro measurement of various steroids in body fluids by competitive protein binding radioassay $J$ clin Endocr 27 973-990,1967

13 Nell, D B , J F Ross and S P Grossman Effects of lesions in the dorsal or ventral striatum on locomotor activity and on locomotor effects of amphetamine Pharmac Blochem Behav 2. 697-702, 1974

14 Premack, D Toward empincal behavioral laws I Positive reinforcement Psychol Rev 66*219-233, 1959

15 Richter, C P Biological Clocks in Medicine and Psychiatry Springfield C Thomas, 1965

16 Schotman, P, M E A Reith, T B Van Wimersma Greidanus, W H Gispen and D De Weid Hypothalamic and Pituttary Hormones and the Central Nervous System with Special References to the Neurochemical Effects of ACTH in Molecular and Functional Neurobiology, edited by W H Gispen New York Elsevier, 1976 pp 309-336

17 Seigel, S Non Parametric Statistics for the Behavioral Sciences New York McGraw Hill, 1956

18 Strong, $\mathrm{P} N$ Activity in the white rat as a function of apparatus and hunger $J$ comp physiol Psychol 55 956-600, 1957

19 Strong, P N and W J Jackson Effects of hippocampal lesions in rats on 3 measures of activity $J$ comp physiol Psychol 70 $60-65,1970$ 